\title{
Regionalism theory: Complementary relationship between technology and space to satisfy the identity
}

\author{
Nada Azzam Mahmood ${ }^{1}$, Ali Mohsen Jaafar al- Khafaji². \\ \{ arch.nada1984@gmail.com ${ }^{1}$, alimkhafaji@yahoo.com $\left.{ }^{2}\right\}$
}

Al-Nahrain University- Department of Architectural Engineering ${ }^{1}$, University of Technology- Department of Architectural Engineerig ${ }^{2}$

\begin{abstract}
During the past years, educational research courses in Europe generally and united Arab nations particularly, have been shifted from its human nature to be interested and supportive of digital technology. Regional Theory is the most important theory that emerged, calling for criticizing architectural digital ideas as "creative" processes, and seeking to restore architectural and technological identity. From this point, the research identified its problems as: The lack of a clear knowledge about the role of regional theory in the interactivity relationship between technology and space to achieve spatial identity, local and sustainable environment. The research aims to achieve an architecture that relies on critical technology that satisfies local identity, with local solutions stemming from moral role of architecture in shaping the environment. To achieve the goal of the research, a descriptive and analytical approach was adopted consisting of two axes: The first aim to Criticizing local space and build strategies of localizing globosity, through generative technology. The second axes include Evaluation and verification of generative technology's indicators in selected architectural models.
\end{abstract}

Key words: technology, place, identity sustainable.

\section{Introduction:}

The invasion of technology to all aspects of life including architecture has led to the emergence of materials relationships between man and his society. Architectural environment oriented towards globalized network community. Human being has become a robotic organism driven by technology; its role is limited to the synthesis between technology and architectural systems. This situation forced architects to rethink their role as a creator. During the twentieth century, philosophers and historians criticized the nature of this relationship, stressing the need for a new approach responds to social needs and interacts with the culture and needs of society. To restore human role in organizing society and being a leader in the process, the study tries to analyze and address methods of achieving spatial identity in the light of universal technology and globalization challenges. Therefore the study divided into 4 main parts: first part analyze the transformation of technology and how it affects architectural culture, second part tries to identify strategies of localizing global technology, third part searching for technological strategies in dissolving globalization and achieving local identity represented in indicators of "glocalised space".

\section{Criticizing local space: localizing globosity}

Technology revolution came with mechanical basis that doesn't respond to human and environmental influences. As what happened to the industrial revolution, technology revolution soon dimmed and voices become louder calling for criticizing architectural digital ideas, doubting its ability to continue being a creative process.

The architect's role during the 19th and 20th centuries was transformed from being the leader of the design process to a technical one whose role is limited to processing information flow that controls the compositions and shapes them in complex structures. To retrieve human role and to restore the relationship between society, architecture and technology, researches and studies started to call for critical sustainable technology, detect complex interactive relationships between technical and social factors. Many concepts emerge such as description of interconnected concepts, from down to top, self-organizing and eco-system. A rethinking of technology and architecture in the age of system means reconsidering the scientific and moral dimensions of architectural transformation and development, (see Fig.1), the following paragraph discusses critical regionalism and its role to combine technology with architecture in "glocalized space". The second paragraph will discuss global experiences that achieve " glocalized space". 


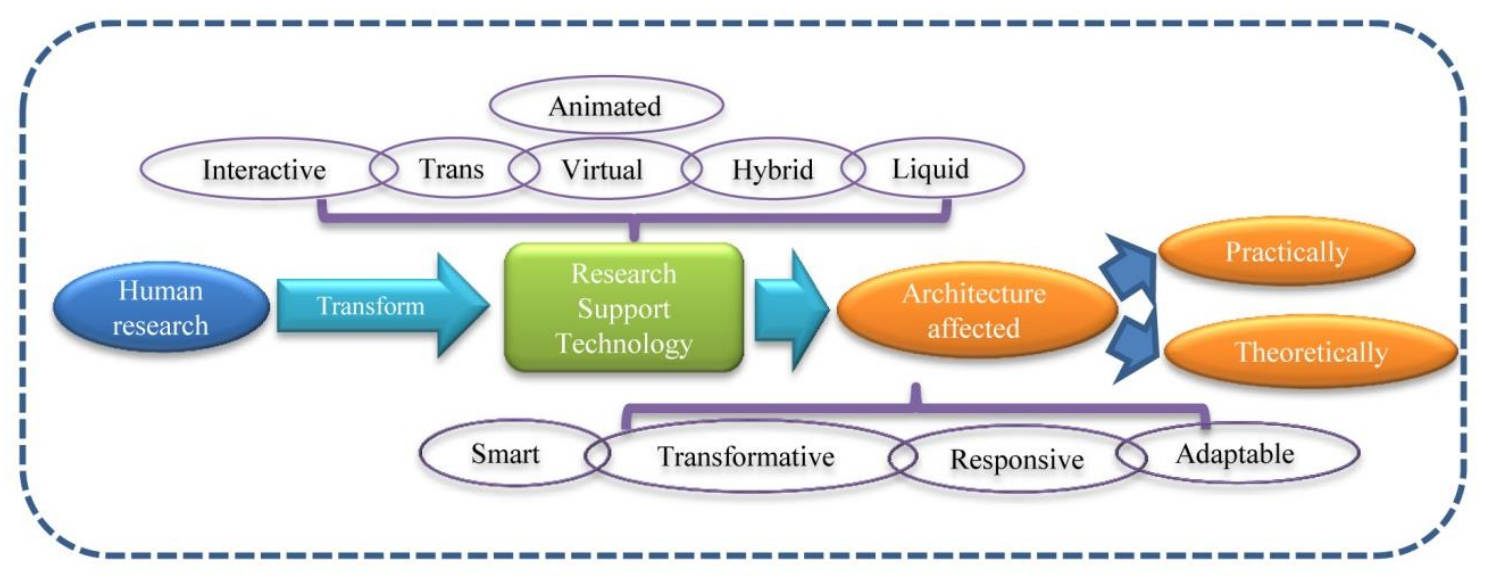

Fig.1. New architectural culture affected by technology

\section{In-betweenness between global technology and local space}

The possibility of realizing identity and continuity between the self and the other through hybrid space called negotiation space, this concept comes as a result of the internal colonization of west and the invasion of globalization to all aspects of life, architecture also affected to produce architecture without its societal identity. The negotiation space is a common hybrid space between the two (the ego and the other) it supposes an intermediate relationship between the two. [2]. Negotiation space is a political space characterized by democracy coming from society and the possibility of architecture in creating its privacy and identity. It's a hybrid space because the identity is in a state of negotiation between the local and the global. Within negotiation process, there are two expressions for hybrid space: the first situation when the global style dominant all existing localism, the second situation happened through dissolving globalization in locality [2] .

Globalization has become a necessity because society's culture is changing towards its participation in global civilization. Also, identity represents community's existence and specifies its characteristics. Between now and the other, between local and global, there must be an intermediate region in which the local character dominates and does not prevent participation with global civilization.

" glocalized space" emerge when (local and global) interact to present 3 possible situations ":

- A parallel relationship, one of which is dominant over the other and the second is dependent on it. In this case, either globalism dominated locality or vice versa. In both cases, there is no interaction but rather an entity that is independent of the other. This situation presents either a place without an identity or a place isolated from the outside world.

- Interactive relationship, in this case, there is one entity for both of them. the shared space is a contradictory complex expressing a common interactive state between the two.

- $\quad$ Hybrid relationship, when the local character formed by dissolving globalization in it, see Fig.2. 


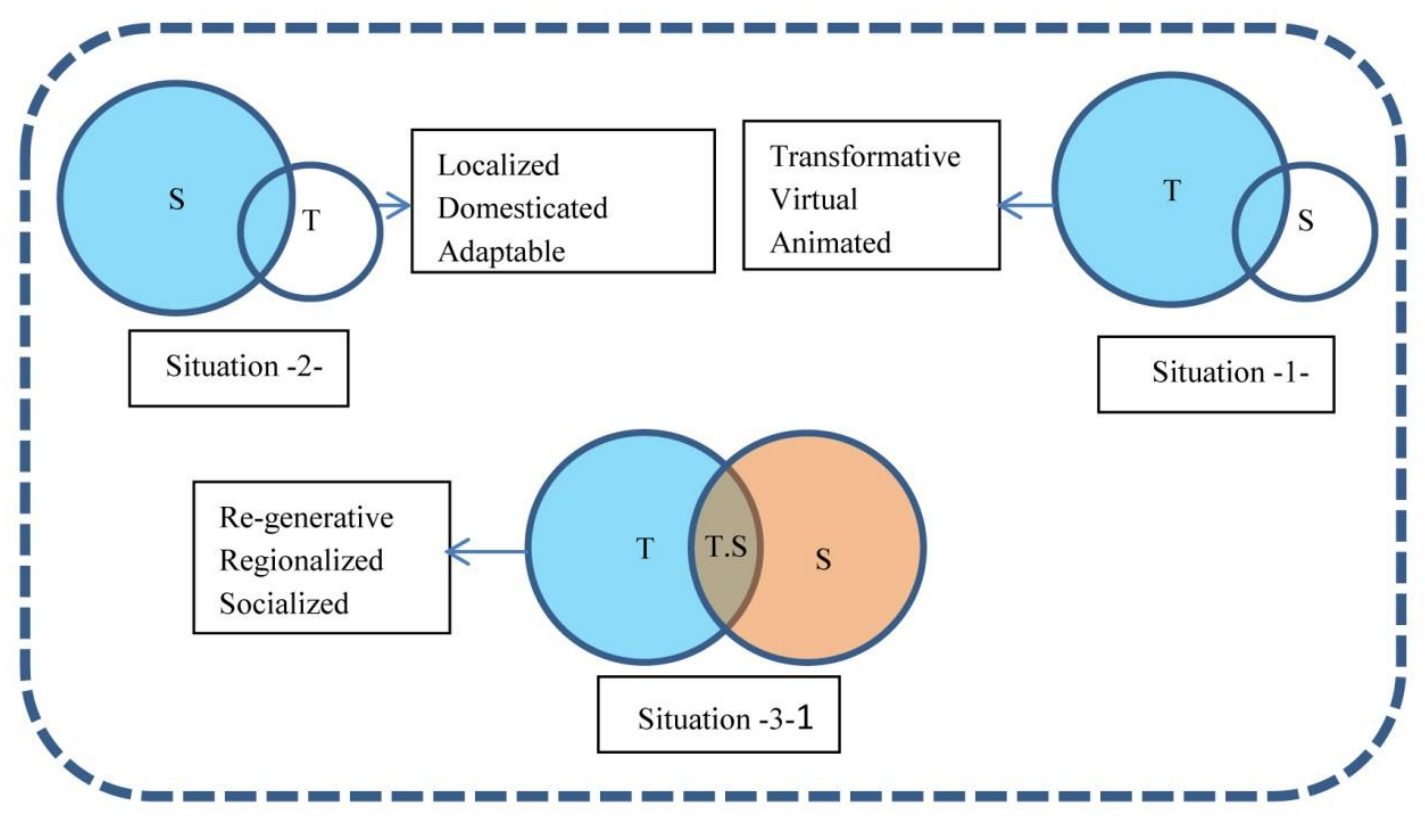

Fig.2. the relationship between technology and space -situation 1 domination of technology on space leads to globalized place situation 2 domination of space upon technology leads to localized place. Situation 3 interaction between technology and space leads to regenerative place

\section{Technology as thought: strategies in dissolving globalization:}

The following paragraph represents the mechanisms and methods in which technology arises by recruiting, refining, adapting, responding and modifying it. In these technics, technology does not create as a generative process but rather are imposed from outside, their characteristics and potentials are changed to be accepted.

\section{4-1 Domestication and locality}

Is a strategy means adapting and taming technology to everyday needs and practices, [12]? The domestication process entails adaption of users and environment to the new technology but this adaptation embedded feedback to the next generation of technology, domestication calls for negotiation of technology with space through appropriation which means bringing technology to the local cultural context while Conversion means redesign meaning, norms, traditions and transfer it back to the outside world. [10]. this process leads to globalizing locality because of the social formation of this technology, which emphasizes the importance of user's role as a leader in the process. The users adapt to technology, fit and respond to it to produce a new generation of it based on the feedback of experiences therefore it gives different products characterized by identity and local nature.

\section{4-2 Adaptability:}

Its ability to achieve identity through its adaptation to the requirements and privacy of place. Adaptive architecture derived from diverse, self-reliant community through selecting and evaluating the use of specific technology that is appropriate to the cultural context it does not depend on one type of technology, develop it to fit with the cultural and natural environment. [3].

\section{4-3 Originality:}

Replacing the old communicative elements with a new, agreed one as the first step in the admission of change in society, these elements become acceptable in reversing social values, absorb and assimilate new forms to become part of the collective memory of each society, suggest and introduce technological rooting technics like integration, borrowing, localization, renewal, reformulation and engagement with Material and intellectual context. [11].

\section{4-4 regenerative and critical:}

Critical technology aims to satisfy spatial identity through the technological generative logic of engagement with space. Regionalism theory is the typical theoretical basis with the generative logic of hybrid technology. It represents a reaction 
to the global effects of stereotyping modernity from onside and postmodern architecture in its call for individualism from the other. It is an attempt towards a culture-sensitive to context and environment, without returning to public architecture. The concept of critical regionalism was first used by Alexander Tzones and Kenneth Leviver and later by Frampton. Regionalism is one of the postmodernist movements in architecture. It is one of the directions that seek to resist being subordinated to globalization; this resistance does not mean returning to the past. Critical regionalism interest with contextual capabilities to give meaning and spirit to the place.

Regional architectures call for:

- The use of modern building materials in architectural elements inspired by ancient architecture.

- Adopting principles and characteristics of local architecture, resulting from accumulated experiences.

- Depend on culture and its principles, focusing on social factors and considering other factors, such as climate, environment and materials which used as complementary elements in regional architecture.

Frampton points out in his book "Towards a Critical Regionalism, Six Points for Resistance Architecture" shows that critical regionalism must give special answers to each local context, taking into account the terrain, climate, light, tectonic rather than scenography and tactile perception rather than visual. Frampton relies on adopting his proposition on daily critical practices to encourage static culture to participate in global civilization, indicating that critical architecture is place architecture more than space architecture and a method of building sensitive to the fluctuations of time and climate [9].

\section{4-5 Hybrids -inbetweenness:}

Critical technology suggests in-between space called locale, it is like a linking space combines places and technologies in a central place between them [5]. Locale is an intermediate ground between: 1- the objectivity and abstraction of location, which understands place as physical dimensions (embed globalism), 2- the subjectivity of understanding place as a mass of subjective feelings (embed localism). Locale is an institutional place in which architects and society contribute greatly through experience gained in Daily practices held in, public square, block, and neighborhood. [1] as shown in Fig.3.

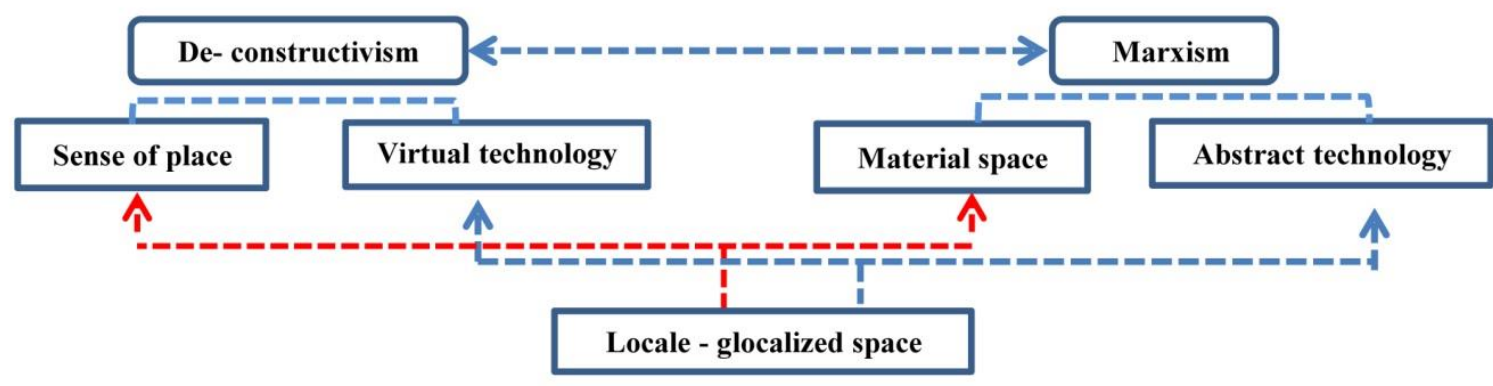

Fig.3. the in between space - locale (glocalized space), in-between technology between abstract and virtual - the in-between space between material space and sense of space.

\section{Technology as fact: Components and Indicators of critical technology :}

The framework of regenerative and sustainable technology represents adopted practice that constitutes an extension of this debate, and support the theoretical framework of the critical regional theory.

Regenerative technology consciously and democratically links human and non-human in constantly changing applications and experiences aimed at improving life. Regenerative technology should, therefore, contain the following factors: see Fig .4.

\section{5-1 Society:}

- Helps society understand the social structure of places

- Enable society in decision making and encourage critical democratic practices life-enhancing practices to create places historically and critically.

- Achieve justice by providing job opportunities for the unemployed

- Interest community culture.

- Stem from daily experience which adopts cultural, an environmental process that links social actors with ecological conditions, glorifying local craft and ecological variables 


\section{5-2 Space:}

- Technology taking into account tectonic history of places.

- $\quad$ Requires being aware of the material conditions of daily life.

- $\quad$ Space ecology

\section{5-3 Technology:}

Combines local crafts with Smart technology

- $\quad$ Social technology combines democratic practices with Sustainable technology.[4]

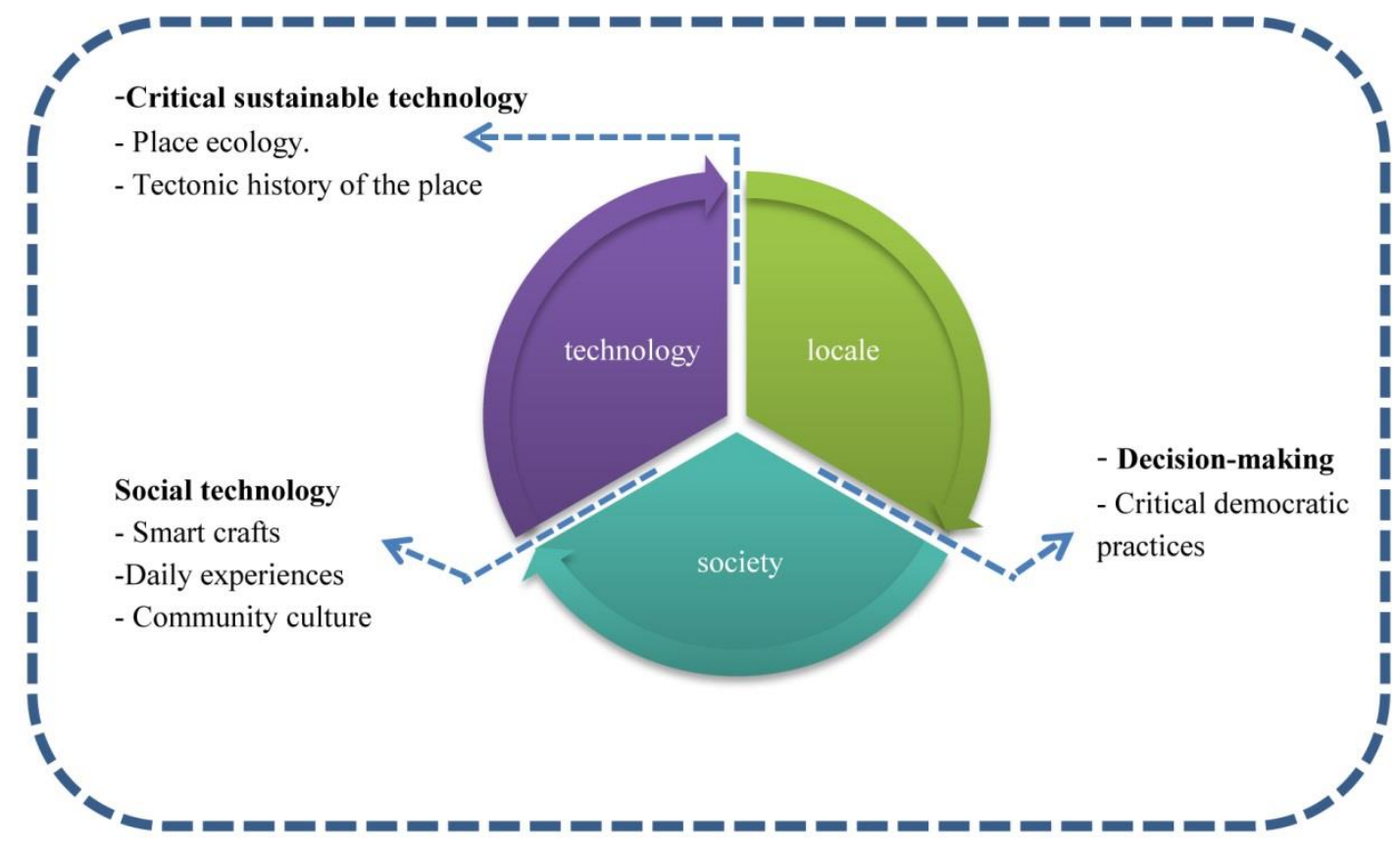

Fig .4. Components of regenerative technology.

\section{$6 \quad$ Evaluation of generative technology :}

The following section represents a group of projects that participated in Architectural Competitions as systematic interventions in the development of technology. The projects are evaluated by architectural specialists in structured questioner prepared according to the indicators of Generative technology specified in the research.

\section{6-1 first project: Miralles Tagliabue - Exibition in Zaragoza 2008}

This project was implemented in Zaragoza, Spain, and was presented at the Spanish Pavilion Design Competition at (2010 Expo) in Shanghai, China, and won the first prize. The design idea is based on achieving architecture that is more related to the environment (climatic and cultural) and more technology. The city is characterized by the local craftsmanship of the wicker basket industry, and this craft has been exploited to reveal the project's possibilities for countless wicker weaving techniques in terms of formality (volumetric and physical dimension). Which derives from the technique of making a wicker basket that they are famous for making, it is a local tradition? The crafts experience combined with smart technology to produce new structural compositions stems from the ecological, sociological matrix. The project required great cooperation between the design and construction team. The structural solution adopted specialized digital programs that used three-dimensional models and provided a system for communication between the architectural team, engineers and manufacturers in the workshops [13] with the help of Fig .5. 

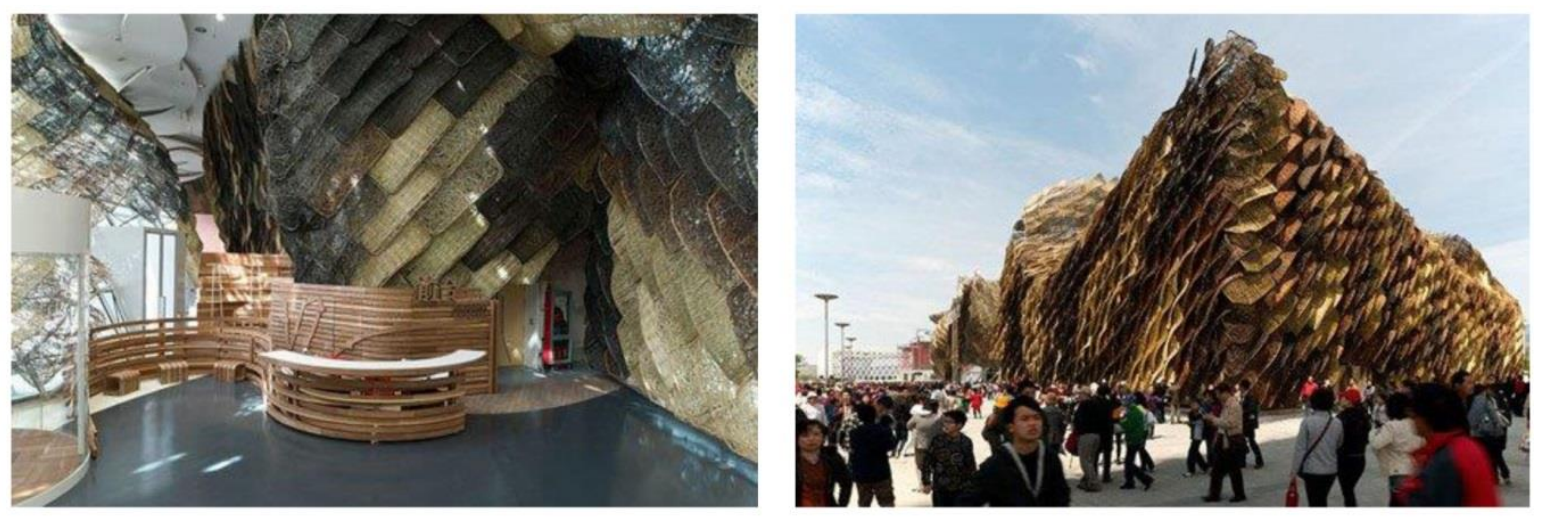

Fig .5.first winner 2010 expo in Shanghai, China http://www.spaceunder.com/editorial/2013/may/20/benedetta-tagliabuearchitecture-and-art-meet-mate/

\section{6-2 second project: Wind and water bar - Vo Trong Nghia - 2008 - Viêt Nam}

Designed by Vietnamese architect Fu Truong Ngia and won the first prize in the International Architecture Award (IAA) for the use of environmentally friendly materials in modern buildings, after it was created in the project "Wind and Water which was designed to be implemented in full from the "bamboo" plant. The project aims to consolidate the architectural works that are created locally with local expertise and environmentally friendly raw materials present in the region. The aim of it was to create an environmentally friendly architecture that the poor can use to make the structure from the woven panels fitted in a local way and with the help of digital programs to develop the initial and construction drawings of the project and relied on Standard construction units and the mechanism of assembly and implementation in sequential forms that reflect the properties of flexible materials. The project has become attractive to tourists from all over the world [14] as shown in Fig. 6.
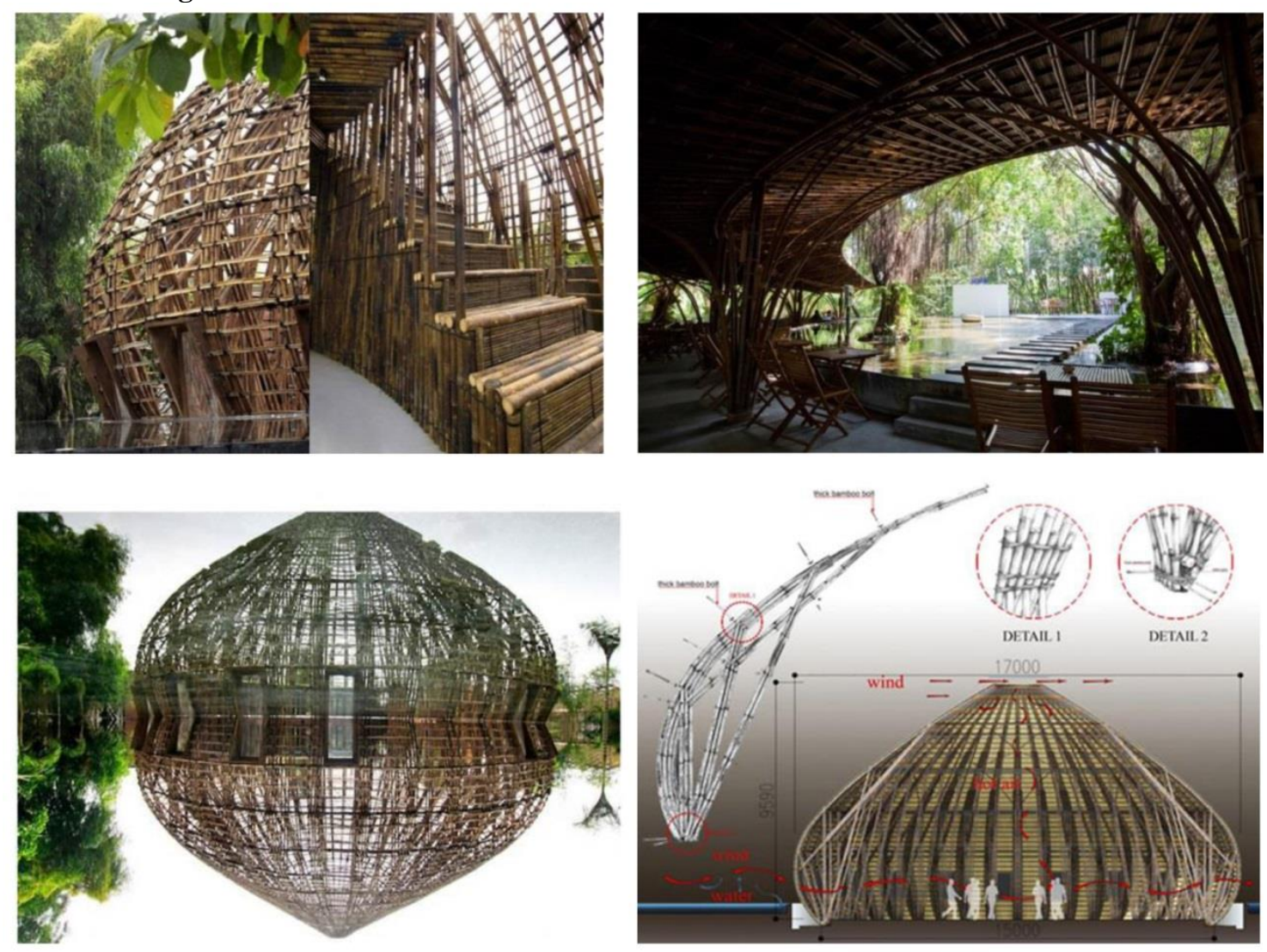

Fig . 6. first prize in International Architecture Award - IAA. 2008

https://autrecarnetdejimidi.wordpress.com/2015/06/28/wind-and-water-bar-vo-trong-nghia-2008-viet-nam/ 


\section{6- 3 case study - winner projects in developing Iraqi - marshes:}

The designers are a winners of Dewan Award for Architecture* and its 2018 theme, "School in the Iraqi Marshes". The marsh architecture uses handicraft with rudimentary technologies to create its architecture from raw materials found in the region, and the use of local expertise. People in the marshes are primitive and lack to the basic requirements of contemporary human beings today.

Challenges are how to achieve a modern life for the residents of the region and provide the infrastructure that responds to the tectonic nature of the reserve, especially after being inscribed on UNESCO's World Heritage List. Integrate smart technology with handicrafts; taking advantage of raw materials; local experiences and regional culture in exploiting the energies exist in making the place. The following are winner projects of Tamayouz Excellence Award - an internationally recognized award judged by a strong international jury board chaired by renowned academics and architects, such as Zaha Hadid, Angela Brad, Jane Duncan, March Glaudemans and others :

\section{6-3-1 Third project: School in marshes - third winner 2008}

Third winner, the concepts based on intelligent use of construction techniques, which can be developed locally. The facade's sensitive color and material palette and the intimacy of the classrooms create a very warm, friendly and human environment [15] as shown in Fig.7.
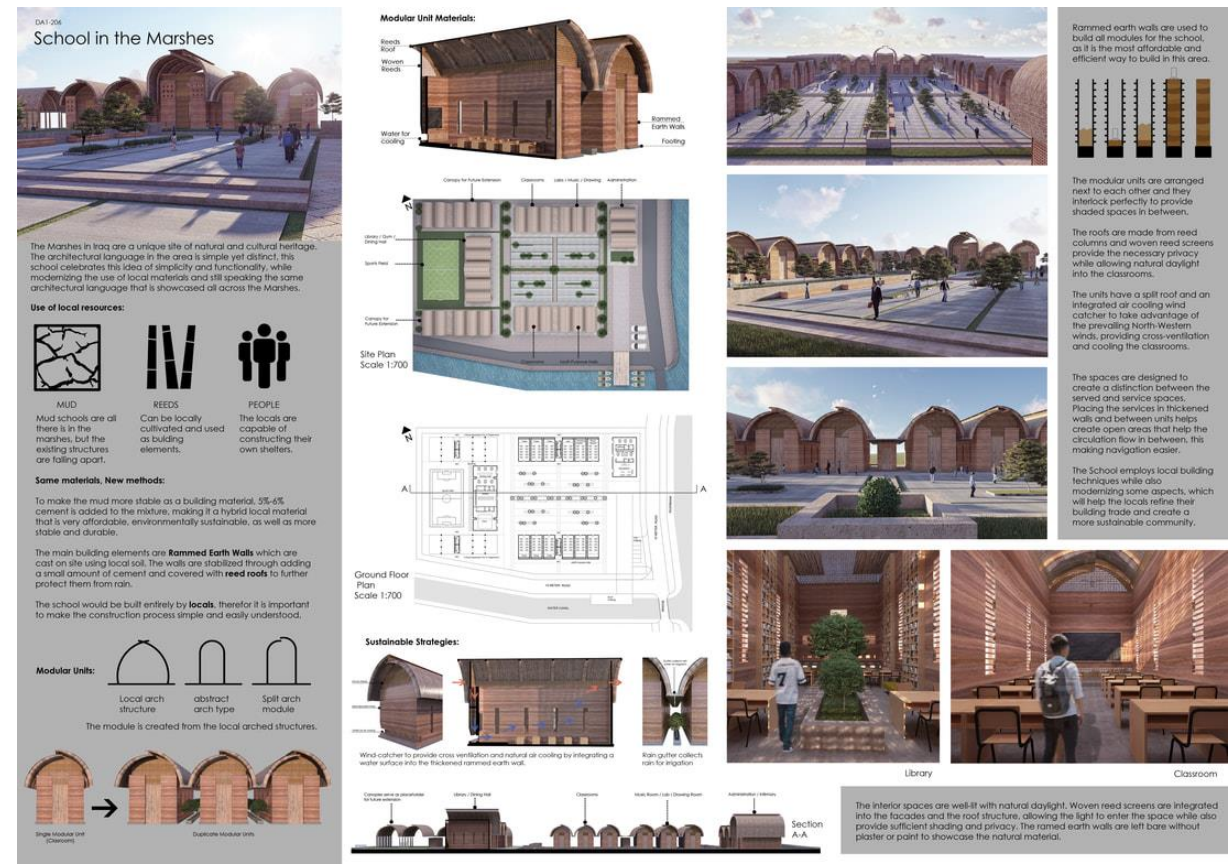

Fig .7. School marshes in Iraq- third winner by Noor Marji, Jordan - Aman 2008 [15].

\section{6-3-3 Fourth project: third winner international center in Iraq marshes Al-Ahwar, 2017}

Place value of the culture, excellent research demonstrates a real commitment to the understanding of place and appropriate solutions. The project connects micro and super macro thinking so essential in identifying local and global challenges, the use of local material and light structure balance the impact of the building with the natural context. It offers possibilities of traditional structure. [16] as shown in Figure 8. 

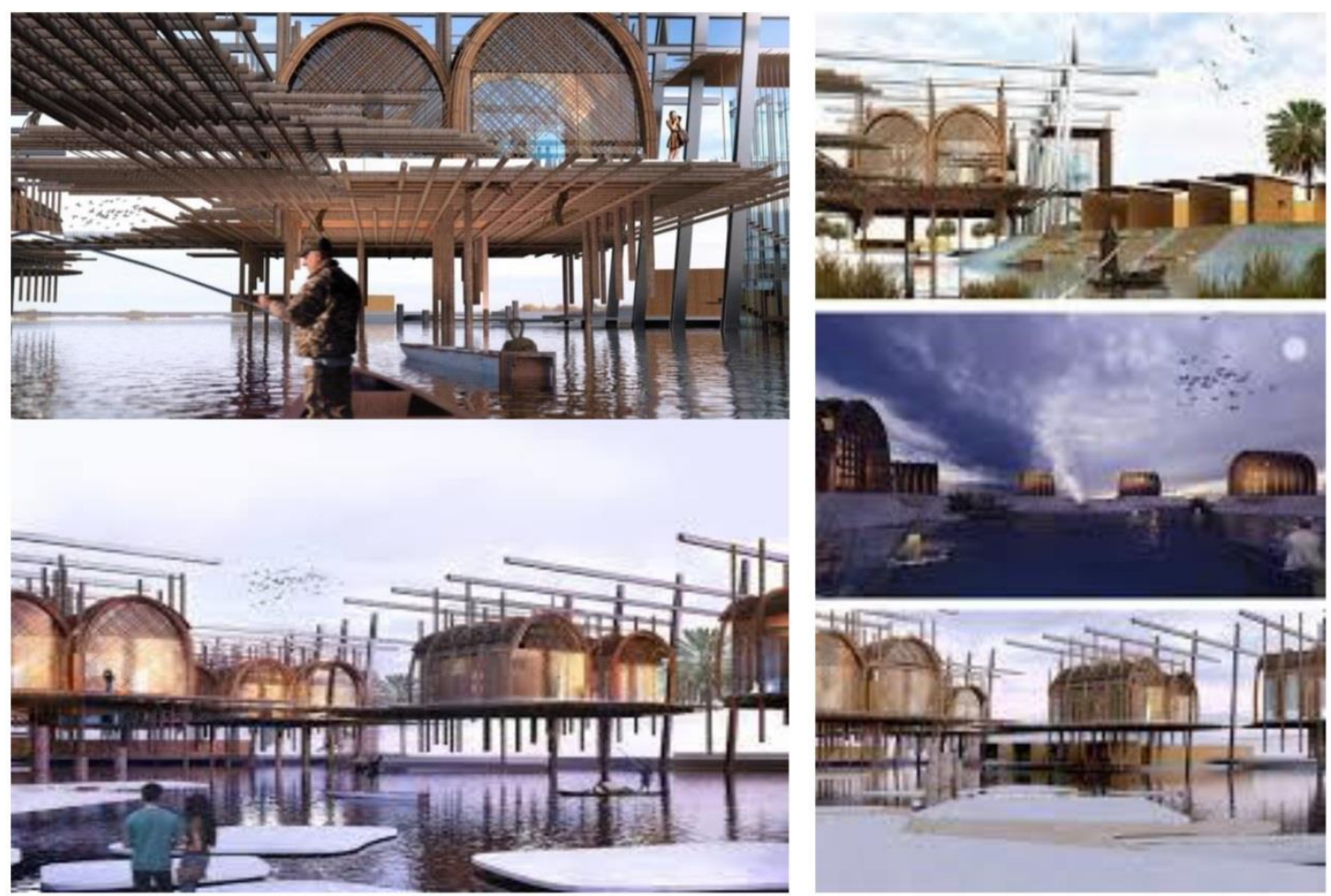

Fig .8. International center in Iraq marshes Al-Ahwar by Zainab Ayad Al-Robaie, 2017 [16].

Results and conclusion:

- $\quad$ As shown in the excel sheets Fig .9. hybridity, adaptability, domestication achieves the lowest value in the selected project which means that designer should spot the light more on how technology can be adaptable to change using smart technology. Results also show a fair relationship between technology space and society Fig.10.

- Second result shows a low value of domestication and that means that technology needs to be more connected to daily life and should be able to share their experience with the external world.

- $\quad$ Results also show the high value of considering the tectonic history of space, the local material, ecology of space and tectonic culture embed them in the technology to generate local places.

- Technology can be regenerative when it starts from down to the top, when taking into consideration the needs of the society.

- Regenerative technology can be domesticated to everyday life by Critical democratic practices calls for lifeenhancing and sustainable experiences which can be shared with the global world.

- Results show that best-localized technology, when the designer generates a new technology stems from the ecology of space using hybrid technology (traditional craft of the region mixed with smart technology). 


\section{Chart Title}

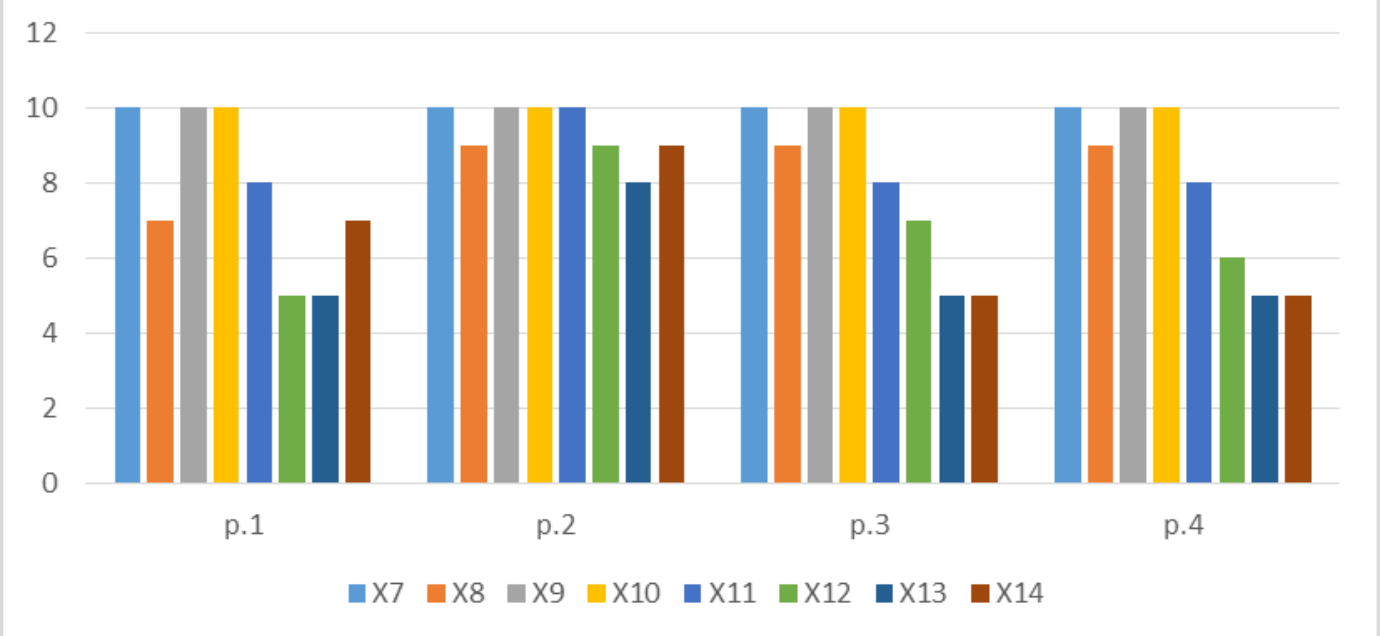

Fig .9. Comparison of indicators values for each project.

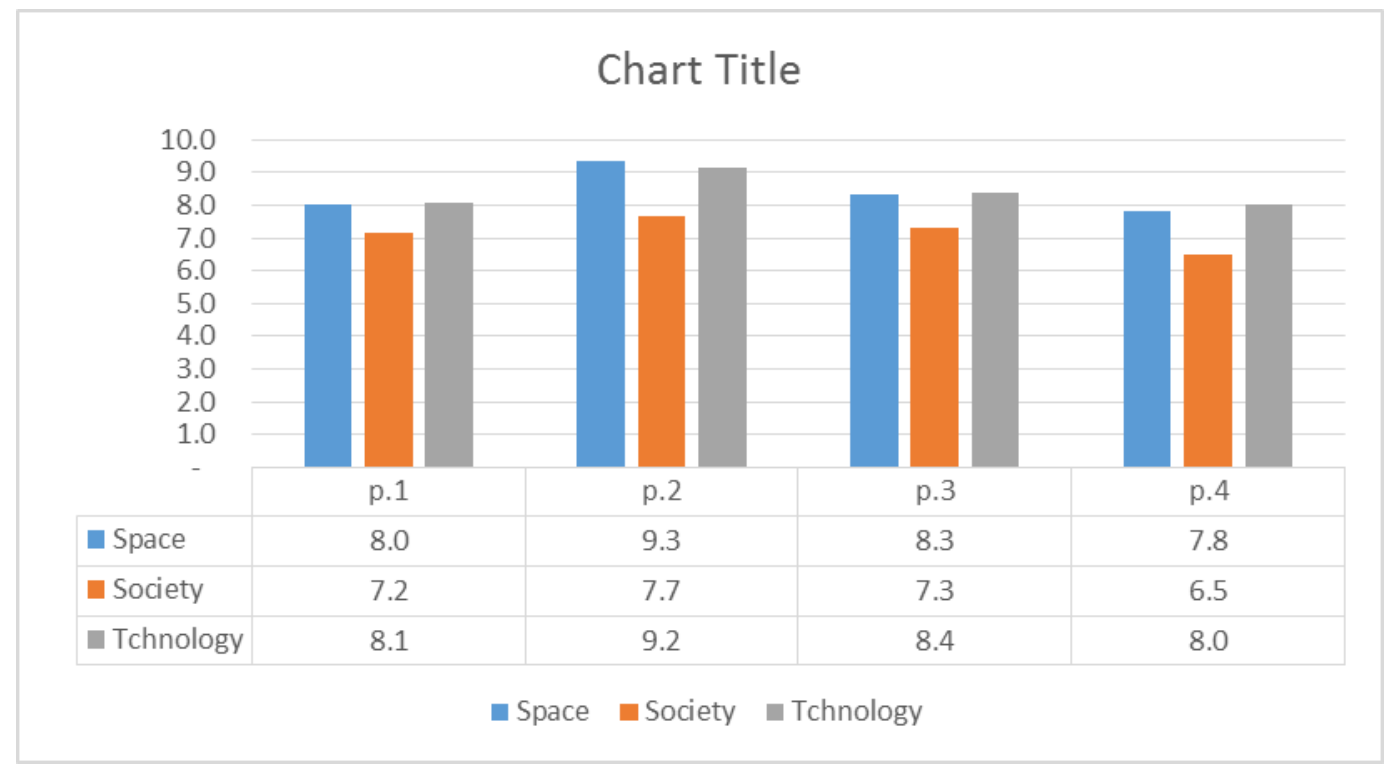

Fig .10.comparison of components of generative technology in the projects

\section{References}

[1] Agnew, J.A.: Place and politics: the geographical mediation of state and society in A Review of The SAGE Handbook of Geographical Knowledge. https://doi.org/10.1080/00045608.2011.650553. P. (2012) .

[2] Al-Khafaji .A.: other in architecture . Dissertation. University of Technology. Department of Architecture Engineering, Iraq- Baghdad. p.38-40( 2008).

[3] Chris.A.: Architecture and Identity:Responses to Cultural and Technological Change. Routledge . U.S.A. , p.190. (2000). 
[4] Cache, B .: Gottfried Semper: stereotomy, biology and geometry Architectural Design “,Vol . 72 .p.28-33.( 2002)

[5] Duncan.J, Ley.D.: space .culture .Representation. Routledge,NewYork. P. 251-71( 1993).

[6] J. Agnew . D. Livingstone .: Handbook of Geographical Knowledge. London: Sage.p. (2012).

[7] Monteiro.E.: Living with technology, Scandinavian Journal of Information Systems .vol.10(1-2) - p.249-253. (1998).

[8].Lie.M , Sorensen.K.: Making technology our own? Domesticating technology into everyday life" . Oslo: Scandinavian University Press. USA. p. 120 (1996).

[9] Moore .S.A.: Technology, Place, and Non-modern Regionalism",Princeton Architectural Press. NewYork. p. 323( 2010)

[10] Monteiro.E.. journal in the internethe information society .vol.14. p. 229- 245 https://doi.org/10.1080/019722498128845. (1998).

[11] Muhammad .A. : The impact of technology in Indigenization strategy Local and contemporary architecture as case study Online resources. Dissertation.University of Technology. Department of Architecture Engineering, IraqBaghdad. P.74 .( 2017)

[12] Ward.K, Punie.Y, Hartmann.K, Berker.T... Domestication of media and technology. Open University Press ., new York. p.2. (2006).

[13] Tsekoura.N.: Spanish Pavilion. First prize in 2010. http://www.spaceunder.com/editorial/2013/may/20/benedetta-tagliabue-architecture-and-art-meet-mate/

[14] Nghia.V: Wind and water bar. Vietnam.(2008). https://autrecarnetdejimidi.wordpress.com/2015/06/28/wind-and-water-barvo-trong-nghia-2008-viet-nam/

[15] Marji.N: School Marshes In Iraq. third winner in timeous-award.(2018) https://www.tamayouz-award.com/news/dewanaward-for-architecture-school-in-the-iraqi-marshes-winners-announcement

[16] Al-Robaie.Z : Interpretation Centre in Iraqi marshland (Al-Ahwar). . Third winner in timeous-award (2017) https://www.tamayouz-award.com/news/winners-announcement-tamayouz-iraqi-students-award-2017

Allen and Unwin .october 2003 Boston and London: Progress in Human Geography 27(5):605-614, DOI:

$\underline{10.1191 / 0309132503 \mathrm{ph} 451 \mathrm{xx}}$ ·p. 62.1987

\section{Appendix:}


Questionnaire Design

Dear Respondent......

After greeting, we put in your hands the questionnaire that was prepared to complete the requirements of our research," Regionalism theory, Complementary relationship between technology and space to satisfy place identity". Please help in answering the paragraphs of the form accurately and objectively, and we guarantee complete personal confidentiality of the answers, knowing that the form that is not answered to all of its paragraphs will be invalid for statistical analysis.

With a great appreciation and respect....

\section{Part one: personal data:}

1- Name:

2- work place :

3- Academic ranking

4- Scientific specialization

Part two: Study Variables

Please put the value from (10) in the appropriate box 


\begin{tabular}{|c|c|c|c|c|c|c|c|c|}
\hline & $\begin{array}{r}\text { Main } \\
\text { variables }\end{array}$ & $\begin{array}{r}\text { Secondary } \\
\text { variables }\end{array}$ & symbol & questions & p.1 & p.2 & p.3 & p.4 \\
\hline \multirow[t]{4}{*}{ 1- } & \multirow[t]{4}{*}{$\begin{array}{l}\text { Space } \\
\text { tectonic }\end{array}$} & $\begin{array}{l}\text { Ecology of } \\
\text { space }\end{array}$ & $\mathbf{X 1}$ & $\begin{array}{l}\text { Address environmental } \\
\text { solutions to climate privacy in } \\
\text { the region? }\end{array}$ & & & & \\
\hline & & \multirow{3}{*}{$\begin{array}{l}\text { Historical } \\
\text { tectonic of } \\
\text { space }\end{array}$} & $\mathbf{X} 2$ & Use of local building materials? & & & & \\
\hline & & & $\mathbf{X 3}$ & $\begin{array}{l}\text { Developing local constructional } \\
\text { craft? }\end{array}$ & & & & \\
\hline & & & $\mathrm{X} 4$ & $\begin{array}{l}\text { Taking in consider Location } \\
\text { characteristics, soil, plants? }\end{array}$ & & & & \\
\hline \multirow[t]{2}{*}{$2-$} & \multirow[t]{2}{*}{ Society } & $\begin{array}{l}\text { Democratic } \\
\text { practices }\end{array}$ & $\mathrm{X5}$ & $\begin{array}{l}\text { Enable society in decision } \\
\text { making? }\end{array}$ & & & & \\
\hline & & Experience & X6 & $\begin{array}{l}\text { Benefiting from daily } \\
\text { experiences in nurturing } \\
\text { technological technics? }\end{array}$ & & & & \\
\hline \multirow[t]{8}{*}{ 3- } & \multirow[t]{8}{*}{ Technology } & Smart & $\mathbf{X 7}$ & $\begin{array}{l}\text { Incorporate local craft } \\
\text { technics? }\end{array}$ & & & & \\
\hline & & Responsive & $\mathbf{X 8}$ & $\begin{array}{l}\text { Affect and respond to the } \\
\text { tectonic, local culture and } \\
\text { crafts? }\end{array}$ & & & & \\
\hline & & \multirow[t]{2}{*}{ Social } & $\mathbf{X 9}$ & Sustain social identity? & & & & \\
\hline & & & $\mathbf{X 1 0}$ & $\begin{array}{l}\text { Vitalize collective memory of } \\
\text { society? }\end{array}$ & & & & \\
\hline & & Domesticated & $\mathbf{X 1 1}$ & $\begin{array}{l}\text { Can the project share the local } \\
\text { technological technics to the } \\
\text { global? }\end{array}$ & & & & \\
\hline & & Original & $\mathbf{X 1 2}$ & $\begin{array}{l}\text { Integration, borrowing, } \\
\text { localization, renewal, } \\
\text { reformulation and engagement } \\
\text { with Material and intellectual } \\
\text { context.? }\end{array}$ & & & & \\
\hline & & Adaptable & $\mathbf{X 1 3}$ & Correspond to changes?. & & & & \\
\hline & & Hybrid & X14 & $\begin{array}{l}\text { Combines virtual with abstract } \\
\text { technology? }\end{array}$ & & & & \\
\hline
\end{tabular}

